\title{
Clinicopathological analysis of salivary gland carcinomas and literature review
}

\author{
HIDEO SHIGEISHI $^{1}$, KOUJI OHTA ${ }^{1}$, GAKU OKUI ${ }^{1}$, SAYAKA SEINO $^{1}$, MIHO HASHIKATA ${ }^{1}$, \\ KAZUHIRO YAMAMOTO ${ }^{1}$, YOKO ISHIDA ${ }^{1}$, KAZUKI SASAKI $^{1}$, TAKAKO NARUSE ${ }^{1}$, \\ MOHAMMAD ZESHAAN RAHMAN ${ }^{1}$, RYO UETSUKI ${ }^{1}$, AKIKO NIMIYA ${ }^{1}$, \\ SHIGEHIRO ONO ${ }^{1}$, HIROSHI SHIMASUE ${ }^{1}$, KOICHIRO HIGASHIKAWA ${ }^{1}$, \\ MASARU SUGIYAMA $^{2}$ and MASAAKI TAKECHI ${ }^{1}$ \\ ${ }^{1}$ Department of Oral and Maxillofacial Surgery; ${ }^{2}$ Department of Public Oral Health, Institute of Biomedical \\ and Health Sciences, Hiroshima University, Hiroshima 734-8553, Japan
}

Received June 23, 2014; Accepted July 21, 2014

DOI: $10.3892 / \mathrm{mco} .2014 .441$

\begin{abstract}
Malignant salivary gland tumors are rare and exhibit a broad spectrum of phenotypic heterogeneity. The objective of this study was to investigate prognostic factors in patients with salivary gland carcinomas and review the results in light of other reports. We retrospectively reviewed 40 patients with primary salivary gland carcinomas who were diagnosed and treated at our institution between 1991 and 2014. Of the 40 tumors, 19 (47.5\%) were mucoepidermoid carcinomas, $11(27.5 \%)$ were adenoid cystic carcinomas, $7(17.5 \%)$ were acinic cell carcinomas, 2 (5.0\%) were myoepithelial carcinomas and $1(2.5 \%)$ was a squamous cell carcinoma. Clinically positive lymph nodes were present in 4 patients (10.0\%). As regards clinical stage, 15 cases $(37.5 \%)$ were stage I, $13(32.5 \%)$ were stage II, 1 (2.5\%) was stage III and $11(27.5 \%)$ were stage IVA. The majority of the patients $(97.5 \%)$ were treated with surgery, of whom $25(62.5 \%)$ received surgery alone and $14(35.0 \%)$ underwent surgery in combination with chemotherapy or chemotherapy and radiotherapy. The median follow-up time for all the patients was 48 months. The disease-specific survival rate at 5 years was $87.1 \%$. We identified a significant correlation between poor survival rate and histological grade (intermediate/high), tumor size (T3/T4), lymph node metastasis (node-positive) and clinical stage (III/IV) using the Kaplan-Meier method ( $\mathrm{P}<0.05$ for each). In addition, the Cox proportional hazards regression analysis confirmed that lymph node metastasis and tumor
\end{abstract}

Correspondence to: Dr Hideo Shigeishi, Department of Oral and Maxillofacial Surgery, Institute of Biomedical and Health Sciences, Hiroshima University, 1-2-3 Kasumi, Minami-ku, Hiroshima 734-8553, Japan

E-mail: shige@hiroshima-u.ac.jp

Key words: salivary gland carcinomas, retrospective study, prognostic factor size were independent prognostic factors for disease-specific survival (hazard ratio $=18.7$ and 15.1, respectively; $\mathrm{P}=0.023$ and 0.037 , respectively). Furthermore, tumor size was found to be a predictive factor regarding recurrence in the multivariate logistic regression analysis (odds ratio $=8.35 ; \mathrm{P}=0.025$ ). Our results suggest that lymph node metastasis and tumor size are significant prognostic factors for patients with salivary gland carcinomas.

\section{Introduction}

Salivary gland carcinomas are rare tumors compared to head and neck squamous cell carcinomas (SCCs) (1). The major salivary glands include the paired parotid, submandibular and sublingual glands, while there is also a significant number of minor salivary glands widely distributed throughout the oral cavity. Salivary gland tumors may originate in either major or minor salivary glands. Tumors originating in the parotid glands account for approximately $70 \%$ of the cases and $<30 \%$ of those tumors are malignant, whereas tumors originating in the submandibular glands account for approximately $10 \%$ of the cases, of which approximately half are malignant $(2,3)$. Tumors originating in the sublingual glands are very rare and the majority are malignant, whereas those originating in the minor salivary glands account for approximately $20 \%$ of all salivary gland tumors and the majority of those are also malignant $(2,3)$. According to the histological distribution described by Spiro (2), mucoepidermoid carcinoma, adenoid cystic carcinoma and adenocarcinoma are common malignant tumors. The initial World Health Organization (WHO) classification of salivary gland carcinomas included a small number of histological subtypes (4), which has increased over a prolonged period of time, emphasizing the need to update due to histological heterogeneity. The latest 2005 WHO classification of salivary gland carcinomas includes 24 different subtypes that present with distinct clinical characteristics and pathological behaviors (5). The rarity and heterogeneity of salivary gland carcinomas generate challenges in regard to histological diagnosis, treatment and outcome. 
Table I. Histological types and locations of salivary gland carcinomas.

\begin{tabular}{lcccccccccc}
\hline & \multicolumn{10}{c}{ Location } \\
\cline { 2 - 10 } $\begin{array}{l}\text { Histological } \\
\text { types }\end{array}$ & $\begin{array}{c}\text { No. of } \\
\text { cases } \%)\end{array}$ & $\begin{array}{c}\text { Parotid } \\
\text { gland }\end{array}$ & $\begin{array}{c}\text { Submandibular } \\
\text { gland }\end{array}$ & $\begin{array}{c}\text { Sublingual } \\
\text { gland }\end{array}$ & Palate & $\begin{array}{c}\text { Buccal } \\
\text { mucosa }\end{array}$ & $\begin{array}{c}\text { Mouth } \\
\text { floor }\end{array}$ & $\begin{array}{c}\text { Lower } \\
\text { gingiva }\end{array}$ & $\begin{array}{c}\text { Upper } \\
\text { gingiva }\end{array}$ & Tongue \\
\hline $\begin{array}{l}\text { Mucoepidermoid } \\
\text { carcinoma }\end{array}$ & $19(47.5)$ & 1 & 0 & 3 & 5 & 2 & 3 & 2 & 2 & 1 \\
$\begin{array}{l}\text { Adenoid cystic } \\
\text { carcinoma }\end{array}$ & $11(27.5)$ & 1 & 2 & 1 & 3 & 1 & 3 & 0 & 0 & 0 \\
$\begin{array}{l}\text { Acinic cell } \\
\text { carcinoma }\end{array}$ & $7(17.5)$ & 1 & 1 & 0 & 1 & 3 & 0 & 1 & 0 & 0 \\
$\begin{array}{l}\text { Myoepithelial } \\
\text { carcinoma }\end{array}$ & $2(5.0)$ & 0 & 0 & 0 & 2 & 0 & 0 & 0 & 0 & 0 \\
$\begin{array}{l}\text { Squamous cell } \\
\text { carcinoma }\end{array}$ & $1(2.5)$ & 1 & 0 & 0 & 0 & 0 & 0 & 0 & 0 & 0 \\
$\begin{array}{l}\text { Total no. } \\
\text { (\%) }\end{array}$ & 40 & 4 & 3 & 4 & 11 & 6 & 6 & 3 & 2 & 1 \\
\hline
\end{tabular}

In the present study, we investigated prognostic factors in patients with salivary gland carcinomas who were diagnosed and treated at our institution and reviewed the available relevant literature.

\section{Patients and methods}

Patients. The records of 40 patients with malignant salivary gland tumors who were treated at the Department of Oral and Maxillofacial Surgery, Hiroshima University Hospital, between 1991 and 2014 were reviewed for pathological characteristics, treatment, recurrence and survival.

Staging and classification. The diagnosis of individual tumors was based on the WHO classification (5). The tumors were also classified using the TNM staging system according to the 5th edition of the General Rules for Clinical Studies on Head and Neck Cancer (Japan Society for Head and Neck Cancer, 2012), which are based on the International Union Against Cancer Classification (6,7). Tumor grading was performed according to the modification of the three-tier grading system proposed by Jouzdani et al (8). Low-grade mucoepidermoid and acinic cell carcinomas were considered to be low-grade tumors, myoepithelial carcinomas were graded as intermediate and high-grade mucoepidermoid carcinoma, adenoid cystic carcinoma and SCC were graded as high-grade tumors.

Statistical analysis. Disease-specific survival was estimated using the Kaplan-Meier method and statistical analysis was performed with a log-rank test. A multivariate survival analysis was performed using the Cox proportional hazards regression model to assess the effect of clinicopathological parameters on disease-specific survival. The Fisher's exact test and a multivariate logistic regression model were used to investigate the effects of clinicopathological parameters on tumor recurrence. $\mathrm{P}<0.05$ was considered to indicate a statistically significant difference.

\section{Results}

Clinicopathological characteristics. We analyzed the records of 12 male and 28 female patients (male:female ratio, 1.0:2.3), with a mean age of 62.4 years (range, 16-89 years). Painless swelling was the most common symptom in 25 patients $(62.5 \%)$, while 7 patients $(17.5 \%)$ had progressive swelling with pain and 1 patient $(2.5 \%)$ presented with a painful ulcerated lesion. The histological types and tumor locations are summarized in Table I. The histological types included mucoepidermoid carcinoma $(n=19,47.5 \%)$, adenoid cystic carcinoma $(n=11,27.5 \%)$, acinic cell carcinoma $(n=7,17.5 \%)$, myoepithelial carcinoma $(n=2,5.0 \%)$ and SCC $(n=1,2.5 \%)$. Histologically, the tumors were classified as low-grade in $23(57.5 \%)$ and intermediate/high-grade in 17 cases $(42.5 \%)$. The tumors were located in the parotid gland in 4 cases $(10.0 \%)$, submandibular gland in $3(7.5 \%)$, sublingual gland in $4(10.0 \%)$ and minor salivary gland in 29 cases $(72.5 \%$ ), with the most commonly affected region shown to be the minor salivary glands. Furthermore, $11(27.5 \%)$ minor salivary gland carcinomas arose from the palate, $6(15.0 \%)$ from the buccal mucosa, $6(15.0 \%)$ from the mouth floor, 3 (7.5\%) from the lower gingiva, 2 (5.0\%) from the upper gingiva and $1(2.5 \%)$ from the tongue. As regards tumor size, 16 cases $(40.0 \%)$ were $\mathrm{T} 1,14(35.0 \%)$ were $\mathrm{T} 2$, $2(5.0 \%)$ were T3 and $8(20.0 \%)$ were T4a. Clinically positive lymph nodes were present in 4 cases $(10.0 \%)$, whereas 2 cases $(5.0 \%)$ were $\mathrm{N} 1$ and $2(5.0 \%)$ were $\mathrm{N} 2 \mathrm{~b}$. Regarding clinical stage, 15 cases $(37.5 \%)$ were stage I, $13(32.5 \%)$ were stage II, $1(2.5 \%)$ was stage III and $11(27.5 \%)$ were stage IVA.

Treatment. For the treatment of affected patients, surgical resection is considered to be the first choice. Neck dissection was performed in all our patients who exhibited clinically metastatic lymph nodes, while adjuvant chemotherapy was administered to patients who had a tumor close to the resection margin or a positive resection margin. The patient treatments are summarized in Table II. In this cohort, 39 patients (97.5\%) underwent surgery and neck dissection was performed in 4 patients $(10 \%)$ 
Table II. Treatment of salivary gland carcinoma patients.

Treatment

\begin{tabular}{lccccc}
\cline { 3 - 5 } Stage & No. of cases $(\%)$ & Surgery & $\begin{array}{c}\text { Surgery } \\
\text { + chemotherapy }\end{array}$ & $\begin{array}{c}\text { Surgery } \\
\text { + chemotherapy } \\
\text { + radiotherapy }\end{array}$ & $\begin{array}{c}\text { Chemotherapy } \\
\text { + radiotherapy }\end{array}$ \\
\hline I & $15(37.5)$ & 12 & 3 & 0 & 0 \\
II & $13(32.5)$ & 8 & 4 & 1 & 0 \\
III & $1(2.5)$ & 0 & 1 & 0 & 0 \\
IVA & $11(27.5)$ & 5 & 1 & 4 & 1 \\
Total no. $(\%)$ & $40(100.0)$ & $25(62.5)$ & $9(22.5)$ & $5(12.5)$ & $1(2.5)$ \\
\hline
\end{tabular}

Table III. Univariate analysis of prognostic factors for survival of salivary gland carcinoma patients.

\begin{tabular}{|c|c|c|}
\hline $\begin{array}{l}\text { Clinicopathological } \\
\text { factors (no. of cases) }\end{array}$ & $\begin{array}{c}\text { 5-year } \\
\text { disease-specific } \\
\text { survival rate }(\%)\end{array}$ & P-value \\
\hline Gender & & 0.81 \\
\hline Male (11) & $90.0 \pm 9.5$ & \\
\hline Female (29) & $85.7 \pm 7.9$ & \\
\hline Age, years & & 0.99 \\
\hline$<55(9)$ & $87.5 \pm 11.7$ & \\
\hline$\geq 55(31)$ & $86.5 \pm 7.4$ & \\
\hline Location & & 0.85 \\
\hline Major salivary gland (11) & $90.0 \pm 9.5$ & \\
\hline Minor salivary gland (29) & $86.1 \pm 7.6$ & \\
\hline Histological grade & & 0.017 \\
\hline Low (23) & 100 & \\
\hline Intermediate/high (17) & $70.3 \pm 13.0$ & \\
\hline Tumor size & & 0.0078 \\
\hline $\mathrm{T} 1 / \mathrm{T} 2(30)$ & $94.4 \pm 5.4$ & \\
\hline T3/T4 (10) & $63.5 \pm 16.9$ & \\
\hline Lymph node metastasis & & 0.016 \\
\hline N0 (36) & $93.5 \pm 4.4$ & \\
\hline $\mathrm{N}$ positive (4) & $66.7 \pm 27.2$ & \\
\hline Clinical stage & & 0.00087 \\
\hline I/II (28) & 100 & \\
\hline III/IV (12) & $56.6 \pm 17.1$ & \\
\hline Resection margin & & 0.70 \\
\hline Negative (29) & $90.5 \pm 6.5$ & \\
\hline Close or positive (10) & $87.5 \pm 11.7$ & \\
\hline
\end{tabular}

with clinically positive lymph nodes. A total of 25 patients $(62.5 \%)$ were treated with surgery alone, while 14 patients (35.0\%) underwent surgery in combination with chemotherapy or chemotherapy and radiotherapy, of whom 9 patients $(22.5 \%)$ underwent surgery with adjuvant chemotherapy and 5 patients $(12.5 \%)$ were treated with a combination of surgery, chemotherapy and radiotherapy. Palliative chemoradiotherapy was
Table IV. Cox proportional hazards regression analysis of prognostic factors for survival of salivary gland carcinoma patients.

\begin{tabular}{lccr}
\hline & \multicolumn{2}{c}{ Disease-specific survival rate } \\
\cline { 2 - 4 } $\begin{array}{l}\text { Clinicopathological } \\
\text { factors }\end{array}$ & $\begin{array}{c}\text { Hazard } \\
\text { ratio }\end{array}$ & $\begin{array}{c}95 \% \text { confidence } \\
\text { interval }\end{array}$ & P-value \\
\hline $\begin{array}{l}\text { Tumor size (T3,T4) } \\
\text { Lymph node }\end{array}$ & 15.1 & $1.19-193.0$ & 0.037 \\
metastasis (positive) & 18.7 & $1.49-234.5$ & 0.023 \\
\hline
\end{tabular}

administered to 1 patient who suffered from stage IVA SCC of the parotid gland. Six patients received 5-fluorouracil-based chemotherapy, 3 received platinum-based chemotherapy and 6 patients received other types of chemotherapy. There was no specific pattern regarding the prescribed chemotherapy regimens and clinical stage. The radiation dose ranged between 30 and 66 Gy. Recurrence developed in 9 patients $(22.5 \%)$ as follows: 3 cases of local recurrence ( 2 high-grade mucoepidermoid carcinomas and 1 acinic cell carcinoma), 1 case of acinic cell carcinoma with local recurrence and secondary lymph node metastasis and 5 cases of lung metastasis (1 acinic cell carcinoma, 3 adenoid cystic carcinomas and 1 SCC). Recurrence occurred in 3 of 10 patients with histologically positive or close resection margins.

Statistical analysis. The median follow-up time for all the patients was 48 months and the overall disease-specific survival rate at 5 years was $87.1 \%$. We investigated the correlation between survival rate and clinicopathological factors such as gender, age, tumor location, histological grade, tumor size, lymph node metastasis, stage and resection margin status using the Kaplan-Meier method. We identified a significant correlation between worse survival and intermediate/high histological grade, large tumor size (T3/T4), lymph node metastasis and advanced clinical stage (stage III/IV) $(\mathrm{P}=0.017,0.0078,0.016$ and 0.00087, respectively) (Table III). As regards treatment, patients who received surgery alone had a better survival rate compared to the other groups (data not shown). To independently evaluate multiple prognostic factors (i.e., histological grade, tumor size and lymph node metastasis), a Cox proportional 
Table V. Univariate analysis of predictive factors for recurrence of salivary gland carcinoma.

\begin{tabular}{|c|c|c|c|}
\hline $\begin{array}{l}\text { Clinicopathological } \\
\text { factors (no. of cases) }\end{array}$ & $\begin{array}{c}\text { No recurrence } \\
(\%)\end{array}$ & $\begin{array}{c}\text { Recurrence } \\
(\%)\end{array}$ & P-value \\
\hline Gender & & & 0.40 \\
\hline Male (11) & $10(90.9)$ & $1(9.1)$ & \\
\hline Female (29) & $21(72.4)$ & $8(27.6)$ & \\
\hline Age, years & & & 0.39 \\
\hline$<55(9)$ & $6(66.7)$ & $3(33.3)$ & \\
\hline$\geq 55(31)$ & $25(80.6)$ & $6(19.4)$ & \\
\hline Location & & & 0.23 \\
\hline $\begin{array}{l}\text { Major salivary } \\
\text { gland (11) }\end{array}$ & 7 (63.6) & $4(36.4)$ & \\
\hline $\begin{array}{l}\text { Minor salivary } \\
\text { gland (29) }\end{array}$ & $24(82.8)$ & $5(17.2)$ & \\
\hline Histological grade & & & 0.023 \\
\hline Low (23) & $21(91.3)$ & $2(8.7)$ & \\
\hline Intermediate/high (17) & $10(58.8)$ & $7(41.2)$ & \\
\hline Tumor size & & & 0.0031 \\
\hline $\mathrm{T} 1 / \mathrm{T} 2(30)$ & $27(90.0)$ & $3(10.0)$ & \\
\hline T3/T4 (10) & $4(40.0)$ & $6(60.0)$ & \\
\hline Clinical stage & & & 0.012 \\
\hline I/II (28) & $25(89.3)$ & $3(10.7)$ & \\
\hline III/IV (12) & $6(50.0)$ & $6(50.0)$ & \\
\hline Nerve invasion & & & 1.0 \\
\hline Negative (35) & $27(77.1)$ & $8(22.9)$ & \\
\hline Positive (5) & $4(80.0)$ & $1(20)$ & \\
\hline Vascular invasion & & & 0.40 \\
\hline Negative (38) & $30(78.9)$ & $8(21.1)$ & \\
\hline Positive (2) & $1(50.0)$ & $1(50.0)$ & \\
\hline Resection margin & & & 0.17 \\
\hline Negative (29) & $25(86.2)$ & $4(13.8)$ & \\
\hline Close or positive (10) & $6(60.0)$ & $4(40.0)$ & \\
\hline
\end{tabular}

Table VI. Multivariate logistic regression analysis of predictive factors for recurrence of salivary gland carcinoma.

\begin{tabular}{lccc}
\hline $\begin{array}{l}\text { Clinicopathological } \\
\text { factors }\end{array}$ & $\begin{array}{c}\text { Odds } \\
\text { ratio }\end{array}$ & $\begin{array}{c}\text { 95\% confidence } \\
\text { interval }\end{array}$ & P-value \\
\hline $\begin{array}{l}\text { Histological grade } \\
\text { (intermediate/high) }\end{array}$ & 3.57 & $0.51-25.1$ & 0.20 \\
\begin{tabular}{l} 
Tumor size (T3,T4) \\
\hline
\end{tabular} & 8.35 & $1.30-53.5$ & 0.025 \\
\hline
\end{tabular}

hazards regression analysis was performed, which demonstrated that lymph node metastasis and tumor size were independent prognostic factors significantly correlated with disease-specific survival (hazard ratio $=18.7$ and 15.1 , respectively; $\mathrm{P}=0.023$ and 0.037 , respectively) (Table IV). Furthermore, to evaluate the predictive factors of tumor recurrence, the associations between recurrence and clinicopathological factors such as gender, age, location, histological grade, tumor size, clinical stage, nerve invasion, vascular invasion and surgical margin were investigated using the Fisher's exact test (Table V). The variables considered to be statistically significant in the univariate analysis (i.e., histological grade and tumor size) were then evaluated using a multivariate logistic regression model. As shown in Table VI, tumor size (T3/T4) was found to be an independent risk factor affecting recurrence (odds ratio $=8.35 ; \mathrm{P}=0.025$ ). Collectively, our results suggest that positive lymph nodes and large tumor size are significantly associated with poor outcome in salivary gland carcinoma patients.

\section{Discussion}

Salivary gland carcinomas are relatively rare and exhibit marked heterogeneity (1). The diversity of their biological characteristics highlights the need for histological grading revisions and has resulted in the description of various tumor subtypes (5). The variety of histological subtypes may be attributed to the histogenetic origin of salivary gland carcinomas. Regezi and Batsakis (9) hypothesized that the presence of stem cell progenitors in the proximal and distal regions of the salivary duct system indicates the original location of related tumors, e.g., mucoepidermoid, adenoid cystic and acinic cell carcinomas arise from excretory duct cells, intercalated duct cells and acinar cells, respectively.

Of the 24 known types of malignant salivary gland tumors, the 2 most common are mucoepidermoid carcinoma and adenoid cystic carcinoma (2). The former is the most common, accounting for approximately $30 \%$ of all malignant salivary tumors, while the latter is the second most common, accounting for approximately $20 \%(2,10)$. In the present study, mucoepidermoid carcinoma was the most common subtype, followed by adenoid cystic carcinoma, acinic cell carcinoma and malignant myoepithelioma in a descending order, which is in accordance with previously reported findings $(2,10)$. With regard to the location of salivary gland carcinomas, the majority of the tumors in the present cohort $(72.5 \%)$ occurred in the minor salivary glands, with the most frequent site of origin being the palate.

As regards prognostic factors, clinical stage, particularly tumor size rather than histological grade, was reported to be the most significant factor for predicting the outcome of patients with salivary gland carcinomas (11). Intriguingly, the authors of that study reported a stage III/IV patient with a tumor sized $>4 \mathrm{~cm}$ who had a poor outcome regardless of histological grade. On the other hand, patients classified as stage I/II, with tumors sized $<4 \mathrm{~cm}$, had a better prognosis despite histological grade (12). These results suggest that advanced both clinical stage and large tumor size are factors associated with poor outcome. In addition, other prognostic indicators such as age, surgical resection margin and lymph node metastasis have been reported (12-14).

In the present study, several clinicopathological factors, including histological grade, tumor size, lymph node metastasis and clinical stage, were identified as critical for disease-specific mortality. However, age and surgical resection margin were not identified as significant predictors. In particular, we found that lymph node metastasis and tumor size were independent prognostic factors indicating worse survival. Recent clinical studies reported that a high mortality rate was significantly 
correlated with lymph node positivity in patients with adenoid cystic and mucoepidermoid carcinomas $(15,16)$. Our results support a strong association between lymph node metastasis and poor survival.

A total of 9 patients in our study exhibited tumor recurrence (3 patients developed local recurrence, 1 patient had local recurrence as well as regional lymph node metastasis and 5 patients had distant metastasis). Of the 4 cases with local recurrence, 2 cases with high-grade mucoepidermoid carcinomas presented with local recurrence and 1 had an apparent positive resection margin. High-grade mucoepidermoid carcinomas recurred locally, despite histological evidence of a disease-free margin in the surgical specimen (17). These results indicate a significant correlation between local recurrence and the high-grade malignancy of mucoepidermoid carcinomas. In addition, adenoid cystic carcinoma was reported to be the most common type of salivary gland carcinoma associated with distant metastasis (18). In the present study, a high frequency of lung metastasis was found among patients with adenoid cystic carcinomas ( 3 of 11 cases), indicating the distinct metastatic capacity of this type of tumor. The univariate analysis identified histological grade, tumor size and clinical stage as the 3 critical factors for recurrence, while the multivariate analysis demonstrated that large tumor size was the most significant independent clinicopathological factor associated with tumor recurrence. These results suggest that not only a high grade of malignancy, but also a larger tumor size are significantly associated with tumor recurrence. Taken together, a large tumor size is significantly associated with poor outcome (i.e., high mortality rate and frequent recurrence), indicating the significance of complete removal of the lesion before it grows to a large-sized tumor.

Recent molecular biology studies have focused on the identification of the specific molecular characteristics of salivary gland carcinomas (19-23). The expression of the centromere protein and spindle assembly checkpoint gene were reported to be significantly correlated with Ki-67 labeling index and clinical stage in primary salivary gland carcinomas $(19,20)$. Furthermore, telomerase activity was found to be significantly higher in high-grade compared to low-grade mucoepidermoid carcinomas (21). With regard to histological type-specific gene expression, androgen receptor expression was found in carcinoma ex pleomorphic adenomas and salivary duct carcinomas (22). In addition, overexpression of epidermal growth factor receptor (EGFR) was identified in mucoepidermoid carcinomas by immunohistochemical analysis (23). Such gene expression may be a reliable marker of clinically advanced stage or tumors of high histological grade. Although surgery or surgery combined with postoperative radiation remain the standard treatment for this type of malignancy, a clinical trial for molecular-targeted chemotherapy using EGFR inhibitors for salivary gland cancer was recently conducted (24). Efforts focused on elucidating the molecular biological characteristics of the specific subtypes of salivary gland carcinomas may lead to improved therapeutic approaches, resulting in better patient outcomes.

\section{Acknowledgements}

This study was supported by a Grant-in-aid (no. 23592963) from the Japanese Ministry of Education, Culture, Sports and Technology.

\section{References}

1. Ellis GL and Auclair PL: Classification of salivary gland neoplasms. In: Surgical Pathology of the Salivary Glands. Ellis GL, Auclair PL and Gnepp DR (eds). WB Saunders, Philadelphia, PA, pp129-134, 1991.

2. Spiro RH: Salivary neoplasms: overview of a 35-year experience with 2,807 patients. Head Neck Surg 8: 177-184, 1986.

3. Speight PM and Barrett AW: Salivary gland tumours. Oral Dis 8: 229-240, 2002.

4. Thackray AC and Sobin LH: Histological typing of salivary gland tumours. In: International Histological Classification of Tumours. Thackray AC (ed). 7th edition. World Health Organization, Geneva, 1972.

5. Eveson JW, Auclair P, Gnepp DR and El-Naggar AK: Tumours of the salivary glands. In: World Health Organization Classification of Tumours. Barnes L, Eveson JW, Reichart P and Sidransky D (eds). IARC Press, Lyon, pp212-215, 2005.

6. Japan Society for Head and Neck Cancer: General Rules for Clinical Studies on Head and Neck Cancer. 5th edition. Kanehara \& Co Ltd., Tokyo, 2012.

7. Sobin LH, Gospodarowicz MK and Wittekind C (eds): TNM Classification of Malignant Tumours. 7 th edition. Wiley-Blackwell, New York, NY, 2009.

8. Jouzdani E, Yachouh J, Costes V, et al: Prognostic value of a three-grade classification in primary epithelial parotid carcinoma: result of a histological review from a 20 -year experience of total parotidectomy with neck dissection in a single institution. Eur J Cancer 46: 323-331, 2010

9. Regezi JA and Batsakis JG: Histogenesis of salivary gland neoplasms. Otolaryngol Clin North Am 10: 297-307, 1977.

10. Ellis GL and Auclair PL (ed): Tumors of the salivary glands. In: Atlas of Tumor Pathology. Armed Forces Institute of Pathology, 3rd Series, Washington, DC, pp80-94, 1996.

11. Spiro RH: Factors affecting survival in salivary gland cancers. In: Controversies in the Management of Salivary Gland Disease. McGurk M and Renehan A (eds). Oxford University Press, Oxford, pp143-150, 2001.

12. Vander Poorten VL, Balm AJ, Hilgers FJ, Tan IB, Keus RB and Hart AA: Stage as major long term outcome predictor in minor salivary gland carcinoma. Cancer 89: 1195-1204, 2000.

13. Vander Poorten VL, Balm AJ, Hilgers FJ, et al: The development of a prognostic score for patients with parotid carcinoma. Cancer 85: 2057-2067, 1999.

14. Renehan AG, Gleave EN, Slevin NJ and McGurk M: Clinico-pathological and treatment-related factors influencing survival in parotid cancer. Br J Cancer 80: 1296-1300, 1999.

15. Min R, Siyi L, Wenjun Y, et al: Salivary gland adenoid cystic carcinoma with cervical lymph node metastasis: a preliminary study of 62 cases. Int J Oral Maxillofac Surg 41: 952-957, 2012.

16. Bai S, Clubwala R, Adler E, et al: Salivary mucoepidermoid carcinoma: a multi-institutional review of 76 patients. Head Neck Pathol 7: 105-112, 2013

17. Rapidis AD, Givalos N, Gakiopoulou H, et al: Mucoepidermoid carcinoma of the salivary glands. Review of the literature and clinicopathological analysis of 18 patients. Oral Oncol 43: 130-136, 2007.

18. Bradley PJ: Distant metastases from salivary glands cancer. ORL J Otorhinolaryngol Relat Spec 63: 233-242, 2001.

19. Shigeishi H, Mizuta K, Higashikawa K, Yoneda S, Ono S and Kamata N: Correlation of CENP-F gene expression with tumor-proliferating activity in human salivary gland tumors. Oral Oncol 41: 716-722, 2005.

20. Shigeishi H, Yoneda S, Taki M, et al: Correlation of human Bub1 expression with tumor-proliferating activity in salivary gland tumors. Oncol Rep 15: 933-938, 2006.

21. Shigeishi H, Sugiyama M, Tahara H, et al: Increased telomerase activity and hTERT expression in human salivary gland carcinomas. Oncol Lett 2: 845-850, 2011.

22. Nasser SM, Faquin WC and Dayal Y: Expression of androgen, estrogen and progesterone receptors in salivary gland tumors. Frequent expression of androgen receptor in a subset of malignant salivary gland tumors. Am J Clin Pathol 119: 801-806, 2003.

23. Locati LD, Perrone F, Losa M, et al: Treatment relevant target immunophenotyping of 139 salivary gland carcinomas (SGCs). Oral Oncol 45: 986-990, 2009.

24. Locati LD, Bossi P, Perrone F, et al: Cetuximab in recurrent and/or metastatic salivary gland carcinomas: A phase II study. Oral Oncol 45: 574-578, 2009. 